\title{
Erasing the Product: The Search for a Design/Build Pedagogy
}

JOHN POROS

Mississippi State University
Design / Build pedagogy has tended to focus on full scale construction with clients outside of the academy. While students learning how to construct in full scale and interact with a client are a plus of this approach, there are also many pitfalls. The greatest of these pitfalls is the overwhelming need to create a completed, functional building over the need for students to understand and explore how design, drawings, and specifications become translated into construction. The studio described in this paper attempts to stand that relationship on its head, minimizing the final product in order to explore more thoroughly the process of communicating construction.

What surprises me most in architecture, as in other techniques, is that a project has one life in its built state but another in its written or drawn state. ${ }^{1}$

\section{-Aldo Rossi}

The quote by Rossi points out how architects in the 1960's and 70's rediscovered the difference between drawn and built architecture. Especially in the early 1970's when the opportunity to build was less frequent, the influence of the drawn project could overshadow built projects. Architects such as Hejduk, Graves, and Eisenman were known for what they drew rather than what they built. Eventually, these architects began to build after they influenced an entire generation of architects who had already begun to build what they had seen drawn.

In some respects the same issues dog the academic design/ build project. Design/build in the academic environment has a wide variety of goals; from exploring the connection between what is drawn to what is built, to engaging with communities and improving people's lives with a built product. When the built product is significant in size and resources, the moral imperative for that product to be useful pulls on the process as a whole. In many instances, this moral imperative overshadows the basic pedagogical intent; to explore the relationship between drawing and building.

Design/Build in the College of Architecture, Art, and Design at Mississippi State University has been undertaken by a collaborative studio between 2 nd year architecture and building construction science students for the past five years. The intent of the collaborative studio has been to expose both these groups of students to actual construction, and to each other as partners in creating built environments. In the past, this collaboration has meant building large scale constructions, mostly pavilions of some sort. The projects have all had a client; an organization who has paid for construction materials and has expected a result that works functionally and aesthetically for them.

While these projects have been successful in many regards, winning national design awards in some cases, the toll on faculty and students has been substantial. The planning required to find clients who are willing to pay the studio's expenses is difficult and the effort by faculty and administrators usually must begin the spring before the fall studio. The studio itself experiences all of the common pitfalls of design/ build studios: not enough time to complete the project by the semester's end, logistical challenges of procuring equipment and material, problems in mobilizing students with their varied academic schedules and talents. The result is usually projects that need to be finished the following semester by faculty or by a special topics class of committed students.

Faculty have been creative in identifying and solving these problems. Projects have moved from design/build by students to design by faculty and then build by students. Logistical issues are made part of the learning process. The scope of projects have been changed to better accommodate time and budget.

Nonetheless, with a client, certain expectations have to be met. A product is required and for many of these projects, a degree of permanency, craft, and functionality is also important. The focus of the studio turns from the collaboration between these young professionals and how they communicate design and construction ideas to the object itself. For the students who commit themselves to the process, the payoff is evident. Those committed students learn issues of construction that cannot be taught simply through instruction or even drawing. The students also learn basic construction techniques and practices, an invaluable experience for a young constructor or designer. Finally, an object is produced that students and faculty can point to and say, "We made that."

The pedagogical question remains, what do we want students to learn from a design/build experience? If construction techniques and procedures are the content, are they better off working for a building contractor to learn the state of the art? If working with a client is the goal, is exposure to a non-profit 
that has engaged a community for years or even decades a better way to teach those skills? The faculty teaching the collaborative studio at our institution have struggled with this question and decided to prioritize the goals of understanding how construction ideas are communicated.

To achieve this goal, the object being constructed must be rethought. Projects at the scale of a building have been abandoned for smaller constructions that still have enough construction difficulties to warrant the need for clear, precise, drawings, and specifications, as well as means and methods. In these small scale projects, the students and faculty become their own clients, removing some of the reality of the project, but also a layer of misdirection and interpretation that having clients entails.

In addition, we have prioritized the communication aspect of design build; the necessity of producing documents that communicate both intent and specificity from designer to builders and back. These include not only the design and construction documents, but also communications back and forth from the builders to the designers during the building process.

Our testing of these principles began in the fall semester of 2017 with what has been termed in our college, "The Collaborative Studio." For the past six years, we have combined the second year architecture students with the second year building construction science students together in a single six credit hour studio. The aim of this combined studio is to not only allow the two professions to interact and begin to understand one another, but bind them together in their learning by making construction the focus. The shared responsibility in the solving constructional problems that both professions have becomes the shared learning experience as well.

For this studio, co-taught between two architecture faculty and two building construction science faculty, we decided to make a bench the object of construction. A bench was chosen because it had enough construction complexity to promote a dialogue between students constructing the bench and students who designed the bench. The size of a bench also lent itself to some challenges, but without making construction completely overwhelming to students. Also, a bench can have enough design elements to promote a discussion about anthropomorphic proportions, style, and even philosophy of the bench designers.

We started by dividing the students into groups of two and three to draw and then build a pre-existing bench. The benches we chose were from the book, We Sit Together: Utopian Benches from the Shakers to the Separatists of Zoar by Francis Cape. These benches were made by utopian societies in the United States for their own use. The thirteen benches chosen ranged from long, simple dining benches to
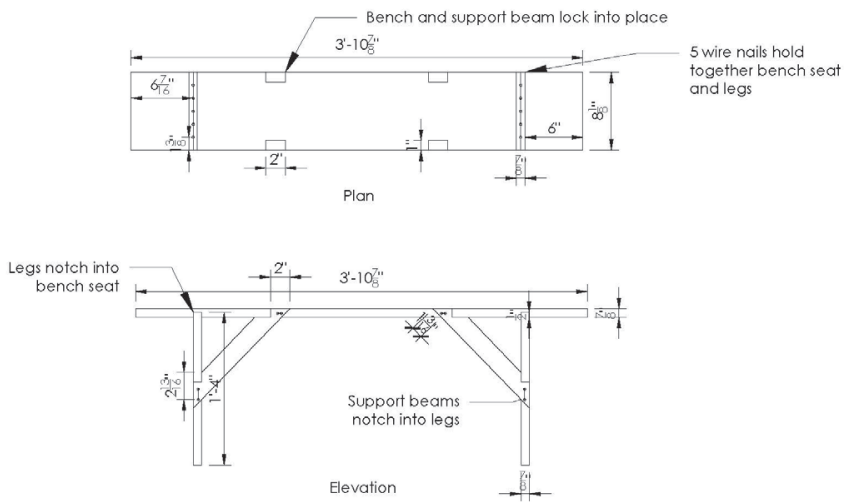

Figure 1: Utopian Bench Measured Drawing.

shorter benches that were more complex in construction. The students were expected to understand the philosophy and culture of these utopian societies as an important part of the project.

Both groups of students, architecture and building construction science, were tasked to take descriptive sketches and photographs from the book of each of their respective benches and draw accurate plans, sections and elevations. They were also asked to provide a template drawing showing how each piece of the bench would be cut out of a piece of lumber or plywood and how much material would that take. This beginning exercise was to impress upon students the importance of clear documentation to allow the construction process to go forward. The documentation also allowed students to begin to work out details of construction in drawing, especially in providing dimensions of the benches' parts.

The first drawings the students produced revealed a lack of understanding on the part of students about the purpose of dimensioning drawings. Students would tend to either provide overall dimensions for the benches or give large strings of dimensions without a sense of hierarchy of the pieces and therefore the dimensions ( Figure 1 Utopian Bench Measured Drawing ). Instruction in pin-up presentations were given so that students understood dimensioning as a hierarchy of providing overall dimensions of the bench when assembled as well as providing the dimensions of particular pieces.

The students then built their benches from their measured and dimensioned drawings. We also asked the students to create a 3 to 5 minute video that documented their experience building the benches. The videos were meant to be a means to students documenting the challenges they had constructing the benches that were unforeseen in their drawings. Unfortunately, for most students the exercise was a simple narration of the construction steps rather than any critical examination. Of course, issues in the construction did arise; determining the connection of parts, the use by students of 


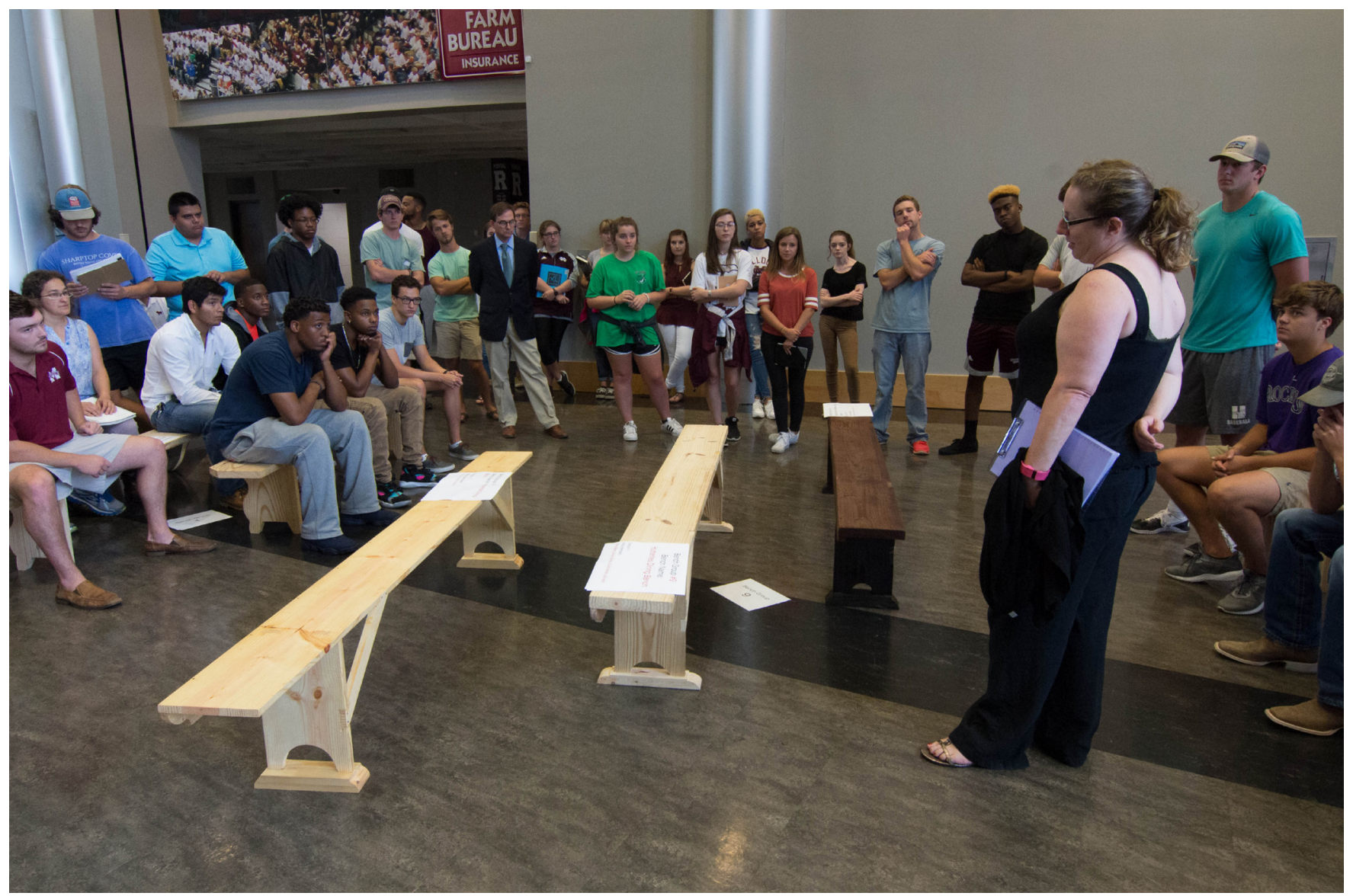

Figure 2: Utopian Bench Review

the cheapest grade of lumber possible who then had to create precise notched and fitted joints, difficulties in the alignment of pieces. These issues were brought out in a formal review rather than in the video, where faculty could examine the benches and discuss with students their particular issues and point out the gaps between knowledge in drawing of an object and knowledge gained from the construction of that object ( Figure 2 Utopian Bench Review ).

The final steps to the project involved the same groups of students that designed and constructed the first bench designing a new bench. Students were instructed to design the new bench based upon the principles of the utopian societies that had produced the previous bench that they built. The new bench had two added requirements of seating three persons and nesting or stacking for easy storage.

The documents that the students were instructed to produce for the new bench design were 2-dimensional orthographic drawings, a material layout template, a step-by-step instruction book for assemblage of the bench, a construction schedule, and a cost estimate. The orthographic and template drawings to be produced were a repeat of the drawings produced for the first bench, which showed an improvement in the understanding of how the drawings could be useful in the woodshop during construction. The step-by-step instruction book was assigned so that students would have to think through the construction process for their design. The students were shown examples of assembly manuals for furniture from IKEA as a template for their instruction book. The IKEA assembly manuals have no words, but instead precise, graphical diagrams for each step of the furniture assemble process. In addition, the IKEA manuals lay out all of the pieces and all of the tools required for assembly. The students' task was to follow this model, adding the steps of actually cutting out the parts ( Figure 3 Design Bench Instruction Manual).

The last pieces of documentation were a construction schedule and a cost estimate. Construction scheduling and cost estimating are skills that the building construction science students needed to be introduced to in their curriculum, but creating these documents also gave the design teams another dimension to measure their project by.

With these documents complete, the student teams were then instructed to exchange their design documents with another team, who would interpret and then build the designed bench. The two teams, design and build, were discouraged from verbally communicating with one another, and were instead allowed to exchange a maximum of three 
10

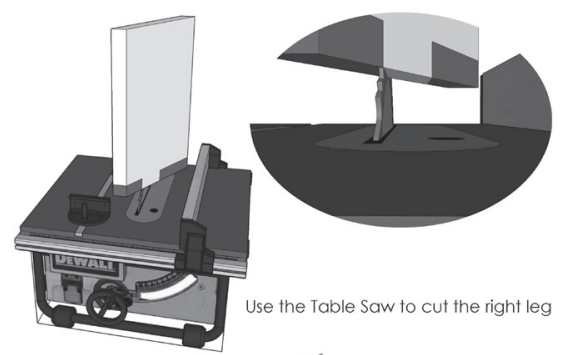

11

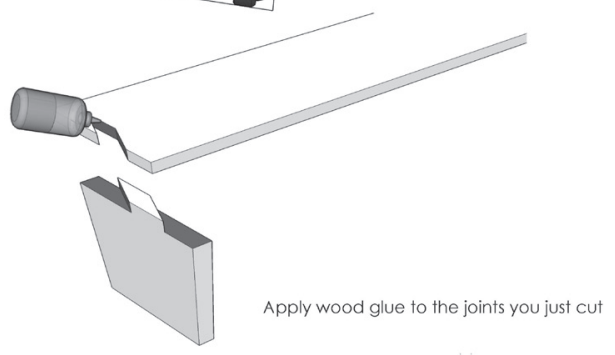

12

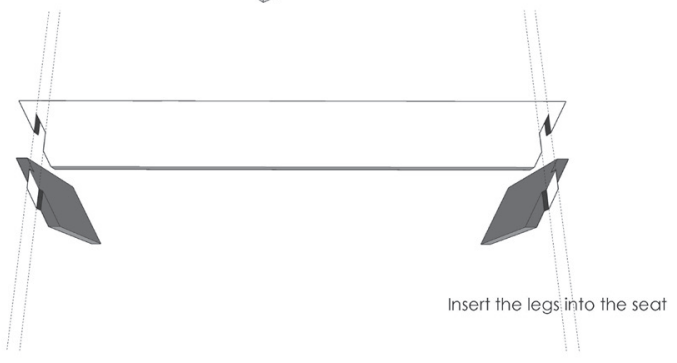

Figure 3: Design Bench Instruction Manual

written Requests for Information (RFI's) between each other. The RFI's could be simply clarifications, but we also encouraged the build team to propose solutions to the design team regarding design problems. For instance, one build team received design documents and very quickly determined that the design would not hold up three persons if it were executed in wood. The build team suggested that the bench as designed was really suited for steel fabrication and the build team's expertise would allow this solution. Although the final design agreed upon by these teams was in wood, these are the types of conversations we wanted to occur between the designers and builders.

In another instance, the build team attempted to fabricate a triangular support rail as per the instruction of the design team. The tools in the woodshop would not allow the fabrication of the part as per the design, which was to glue six layers of plywood together and then make an angled cut on the table saw. The stacked plywood proved too much to cut at once for the table saw. ( Figure 4 Attempting to cut support rail) The build team suggested building a hollow triangular tube by beveling the edges of three sides of plywood and gluing them together. The design team agreed to the change and the build team then executed it.
These student designed benches were then reviewed where a member of the design team and the construction team stood next to the finished bench ( Figure 5 Bench II Designer \& Constructor). The review, while certainly open to all of the typical issues of design and craft, was meant to discover the gaps and bridges in communicating intent between designer and builder. Students were required to evaluate their performance on both the designer and builder side in the form of a written survey as well.

In the written surveys, the students who designed the benches assessed the students who built the benches. The survey asked if the bench was executed according to the plans, specifications, and quality required by the design team. The survey also asked the design team about how much and how well the build team communicated with them, whether errors and changes were found during the building process, and how the design team might re-approach the design given what they know after the build.

The design teams were mostly honest about the quality of craftsmanship that the build teams produced in the survey. The RFI process seemed to work in most cases according to the survey, where there was at least some dialogue between teams in response to questions and issues in the construction documents. According to one team in response to the question, "Did the build team identify a deficiency and/or error in the construction documents? Did the build team provide a solution/s or alternate approach/s?, they responded, "The build team noticed that there was dimension missing in the construction documents, and before advancing on to the next step in the directions, they clarified the issue so as they were not to assume the size of the dimension. The build team waited for instruction before preceding (sic) as this dimension was important to the design of the bench." In this way, the experience of the design and build teams mirrored the process followed during building construction.

In most cases, the builders realized they needed permission from the designers to change the design or materials. There were some cases where builders made unilateral changes to the bench design and the designers made it clear in the survey that they were not happy about not being consulted, even if they agreed with the result. One design group member commented, "I would have considered the stability of the bench more if asked to do this again. Also, I would ask the build team exactly what they intended on adding to the bench instead of just letting them add stability without knowing where."

Students realized that there were problems with the division of labor between design and construction. One group commented, "If I were to approach this project differently, I would like to communicate more with the design team to fully understand design, or maybe even work directly with the design team in building the project." Students discovered 


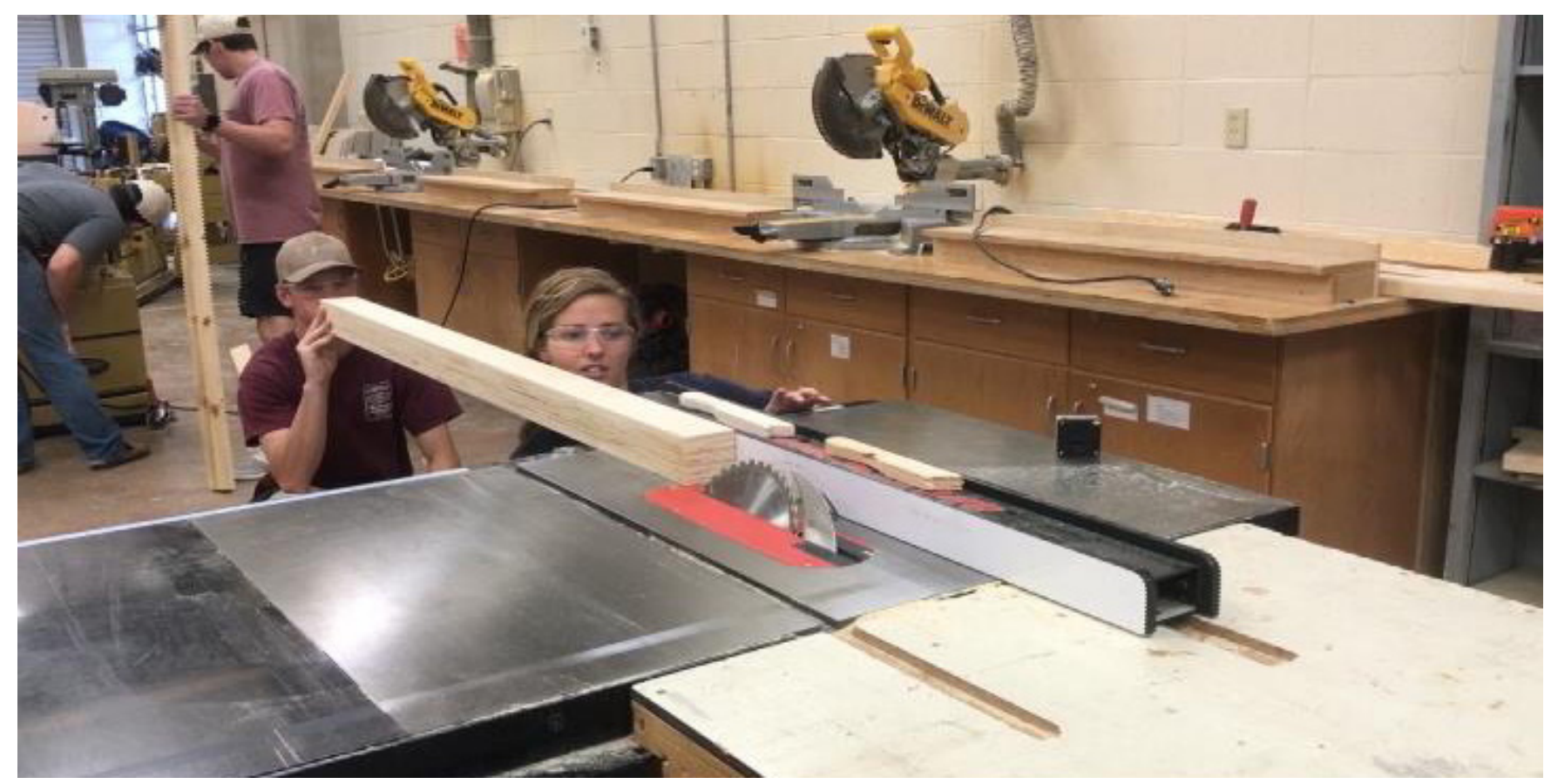

Figure 4: Attempting to cut support rail

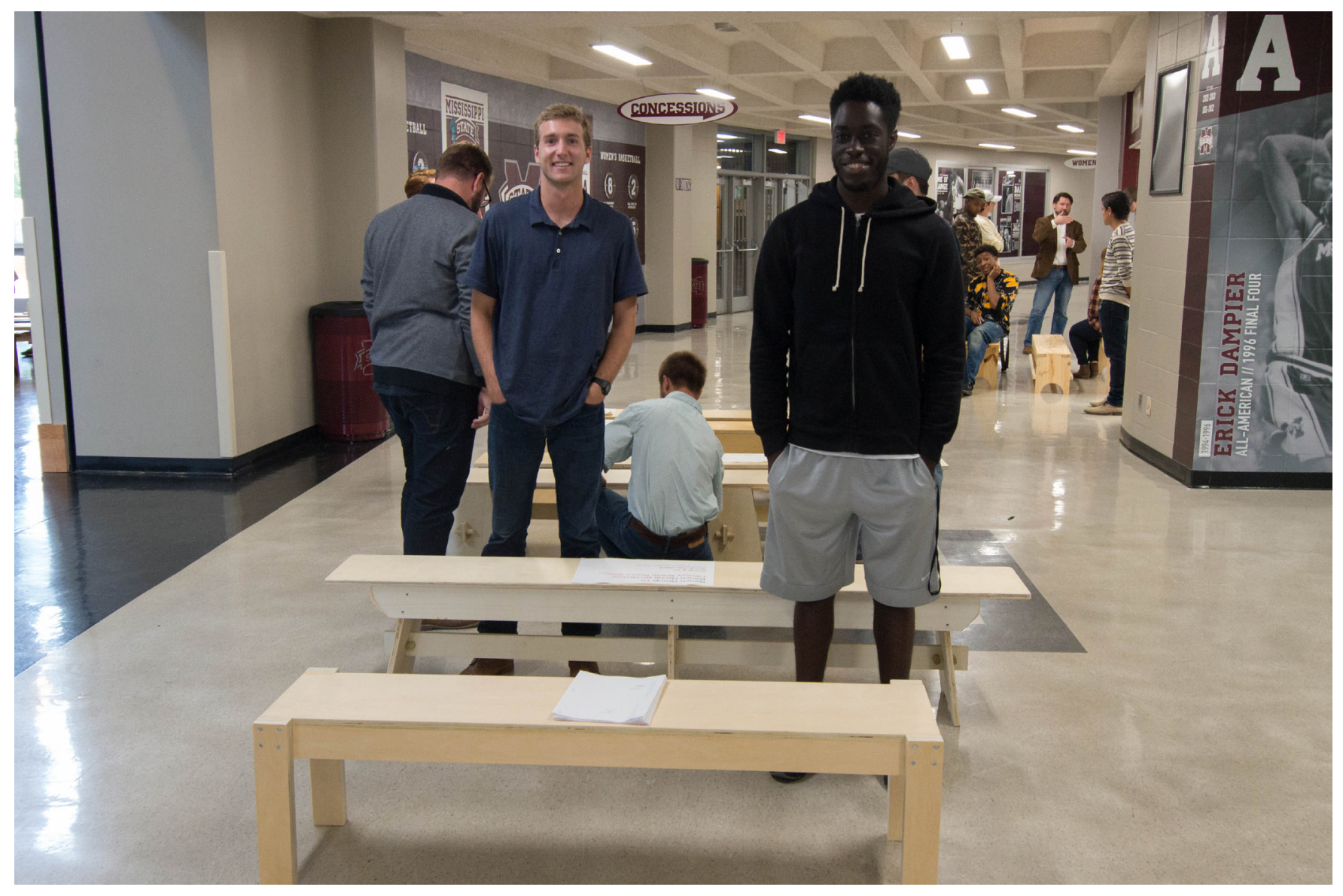


they needed to observe the construction process of the bench at intervals to make sure the design intent was being carried out by the building team. One team wrote, "Just as architects meet with the build team throughout the construction process, I would've wanted to have a designated meeting times with the build to make sure they were executing our designs as we intended."

The intent of the project, to focus attention on the process of design / build rather than the product, was successful relative to previous forms of the studio where the logistics of large scale construction overwhelmed every other issue. The removal of any outside client, reverting to the traditional conversation between student and teacher to fill that role, also allowed the process to be examined in more detail. In changing our design / build semester from one that was outwardly focused to inwardly focused, the faculty also gained some perspective on the role of the client in design / build. Many times we hear that the difficulty in design / build is the interaction with the client; how the client would not warm up to a proposal by students and faculty, or could not make decisions, or was even disengaged from the process.

The problem is usually not with clients in academic design build; clients are generally pliable and just happy to receive the attention of students and then the final product. The problem is more likely with the process. Short interactions do not let all the voices in a community be heard, only the loudest ones. Even when all the voices are heard, a need or desire can take months to form in the minds of a community.

Only where there is a sustained effort with a community, where the academy becomes a member of the community, does a politics between the academy and the community form that allows real work to be done for the community. Otherwise the product of design-build can become a politely received gift, where the recipient is thankful for the gesture but then the product is shuffled away to languish unused.

We realized that we could not provide that level of interaction within the confines of a one semester design / build project. Thus, we made the students clients to each other; the design team for the second bench was the client for the build team. The issues of trust and understanding do not go away; the teams still need to communicate and be truthful with one another for a successful project to occur. The existing familiarity between students, however, makes this exchange less of a leap than with an outside client who students are generally frightened to challenge.

The greater opponent to learning in design / build is the logistics of full scale construction; the massive effort required to schedule, acquire materials, and divide student manpower in a useful way. Certainly the lessons of logistics are powerful and can be brought into the studio, but many times the logistical issues overwhelm everything else so that a 'get it done' mentality overwhelms all other learning. In our attempt to 'erase the product' by scaling back the construction to a bench, we brought attention back to the process of designing and building.

Our retreat from these issues of client, of complex construction and logistics, might be seen as failing to engage important aspects of design / build; we plead guilty to this charge. However, the concerns stated above must be addressed to become more than a feel good exercise on both the academic and client side. For us, realizing that we were not achieving those goals led us to a more narrowly defined scope for design / build learning.

While the design and construction of a simple bench leaves other lessons on the table, it also forces concentration on some of the key aspects of designing and building; the gap between imagining a construction and its realization and thus the necessary dialogue between designer and builder.

\section{ENDNOTE}

1 Rossi, Aldo. A Scientific Autobiography. ( Cambridge, MA: MIT Press). 1981. 